\title{
The effect of alcohol use on academic performance of university students
}

\author{
Menizibeya Welcome Osain*, Vladimir Pereverzev Alekseevic \\ From $1^{\text {st }}$ International Congress on Neurobiology and Clinical Psychopharmacology and European \\ Psychiatric Association Conference on Treatment Guidance \\ Thessaloniki, Greece. 19-22 November 2009
}

\section{Background}

Alcohol use by students is a major public health problem, leading to the Secondhand Effects - decrease in academic performance, injuries, blackouts, alcohol dependence etc.

\section{Aim}

To determine the extent of alcohol use on academic performance of university students.

\section{Materials and methods}

Students $(\mathrm{n}=46$, mean age $-21 \mathrm{yrs})$ from three major universities (Belarusian State Medical University, Belarusian State Agro-Technical University and Belarusian State National Technical University) in Minsk, Belarus agreed to participate in the randomized anonymous study. All participants received questionnaire containing the AUDIT, MAST, CAGE and other alcohol related questions. Examination scores of each participant were filled into the questionnaire on "Academic Performance" from their examination booklets and were controlled by our researcher, Dr. MO Welcome. Academic performances (the Grade Point Average and the effectiveness to sit for examinations) of all participants from the 1st to 6th semesters of university education were used as objective criteria for problems related with alcohol use. The Pearson $\chi 2$ and Student's t-tests were employed for analysis of results. The probability value for significance was set at $\mathrm{p}<0.05$.

\section{Results}

Alcohol and non-alcohol users were 41.3\% and 58.7\% respectively. Among alcohol users, the average quantity of alcohol used by one person per month was $37 \mathrm{ml}$ of

Department of Human Physiology, Belarusian State Medical University, Minsk, Belarus absolute ethanol. A 10.9 - 11.4\% higher rate of academic performance was noted among the non-alcohol users only in the 3rd, 4th and 5th, 6th semesters. The cases of injuries and blackouts were higher among the alcohol users by approximately 35 times.

\section{Conclusions}

This study shows that alcohol use even in moderate doses leads to decrease in academic performance. The absence of any difference in academic performance among the non-alcohol and alcohol users on the 1st and 2nd semesters was probably conditioned by the large number of students (75\% of all alcohol users) who reported alcohol use only in the university. This is because there is a time factor for alcohol effects to be manifested: dose-time response effect of alcohol use negative effect of alcohol use on intellectual activities of students, using academic performance as a criterion, increases with increase in time and dose of alcoholic drinks.

Published: 22 April 2010

doi:10.1186/1744-859X-9-S1-S215

Cite this article as: Osain and Alekseevic: The effect of alcohol use on academic performance of university students. Annals of General Psychiatry 2010 9(Suppl 1):S215. 